\title{
GBEP
}

\section{A organização do ensino na rede pública estadual paulista: análise a partir da teoria crítica da sociedade}

Anoel Fernandes

http://dx.doi.org/10.1590/S2176-6681/323712627

\section{Resumo}

Estudo de caráter bibliográfico sobre o surgimento dos conceitos de "ciclos" e "progressão continuada" e a forma como foram inseridos na rede pública estadual paulista. Apesar de criados com finalidades e contextos distintos, a Secretaria de Educação do Estado de São Paulo (SEE), ao reorganizar a rede pública estadual paulista em 1998, realizou a junção dos ciclos com a progressão continuada. Tendo como referencial de análise a teoria crítica da sociedade, constata que os fechamentos dos universos político e da locução realizados pela linguagem oficial, ao sancionarem os conceitos de ciclos e progressão continuada como pertencentes à mesma forma de organização do ensino, podem remeter os professores ao pensamento unidimensional, e, por conseguinte, à concepção dos ciclos e da progressão continuada como sinônimos, tal como propõe a SEE.

Palavras-chave: ciclos; progressão continuada; linguagem oficial, Estado de São Paulo. 


\section{Abstract \\ The organization of education in São Paulo state public schools: analysis from the critical theory of society}

The present study - of bibliographical character - aimed to identify the emergence of the concepts of "cycles" and "continued progression", as well as how such concepts were inserted in São Paulo's public schools. It was found that the cycles and the continued progression emerged with different purposes and in distinct contexts. In order to reorganize the educational system in public schools, the Secretary of Education of the State of São Paulo (Secretaria de Educação do Estado de São Paulo - SEE) implemented the joint of cycles and continued progression in 1998. Theoretically grounded on the critical theory of society, it can be seen that when the closings of the universes of discourse and politics performed by the official language attest the concepts of cycles and continued progression, as belonging to the same form of organization of teaching, they can lead teachers to the one-dimensional thinking, and, consequently, teachers may conceive cycles and continued progression as synonyms, just like SEE.

Keywords: cycles; continued progression; official language, São Paulo State.

\section{Introdução}

As discussões sobre a forma de organizar o ensino perpassaram o século 20 e adentraram o século 21. Tal temática foi foco da Lei $\mathrm{n}^{\circ}$ 9.394/96 - Lei de Diretrizes e Bases (LDB) -, na qual a educação básica foi organizada em três níveis: educação infantil, ensino fundamental e ensino médio. De antemão, ressalta-se que a LDB não será tomada aqui como ponto de partida, mas será discutida com o intuito de apontar as possibilidades de organização da educação básica após sua promulgação. Em seu artigo 23, a LDB incentiva a flexibilidade da organização da educação básica da seguinte maneira:

A educação básica poderá organizar-se em séries anuais, períodos semestrais, ciclos, alternância regular de períodos de estudos, grupos não seriados, com base na idade, na competência e em outros critérios, ou por forma diversa de organização, sempre que o interesse do processo de aprendizagem assim o recomendar. (Brasil. Lei nº 9.394, 1996, art. 23).

Diante dessas novas possibilidades de organização sustentadas pela LDB, que, por sua vez, "estimularam" o rompimento com o modelo seriado, o Conselho Estadual de Educação do Estado de São Paulo (CEE), no ano de 1997, aprovou a Indicação no 8/97 e a Deliberação nº 9/97, nas quais se 
legislou a reorganização do ensino fundamental na rede pública estadual paulista da seguinte maneira:

Artigo $1^{\circ}$ - Fica instituído no Sistema de Ensino do Estado de São Paulo o regime de progressão continuada, no ensino fundamental, com duração de oito anos.

$\S 1^{\circ}-\mathrm{O}$ regime de que trata este artigo pode ser organizado em um ou mais ciclos.

$\S 2^{\circ}$ - No caso de opção por mais de um ciclo, devem ser adotadas providências para que a transição de um ciclo para outro se faça de forma a garantir a progressão continuada.

$\S 3^{\circ}$ - O regime de progressão continuada deve garantir a avaliação do processo de ensino-aprendizagem, o qual deve ser objeto de recuperação contínua e paralela, a partir de resultados periódicos parciais e, se necessário, no final de cada período letivo. (São Paulo. CEE. Deliberação $n^{\circ}$ 9, 1997).

Baseada na referida Deliberação, a Secretaria de Educação do Estado de São Paulo (SEE), por meio da Resolução no 4, de 15 de janeiro de 1998, em seu artigo $1^{\circ}$, resolveu organizar a escola em dois ciclos de quatro anos cada, sendo assim disposto:

As escolas da rede estadual organizarão o ensino fundamental em regime de progressão continuada por meio de dois ciclos:

I - Ciclo I, correspondente ao ensino de $1^{\mathrm{a}}$ a $4^{\mathrm{a}}$ séries;

II - Ciclo II, correspondente ao ensino da $5^{\mathrm{a}}$ a $8^{\mathrm{a}}$ séries.

Um fator que no presente artigo se discute é a associação que foi estabelecida no Estado de São Paulo entre a organização do ensino por $\operatorname{ciclos}^{1}$ e a progressão continuada, pois a SEE, no momento da implantação, acabou realizando a junção destas e consolidando os ciclos e a progressão continuada como pertencentes à mesma forma de organização do ensino. No entanto, ao buscar na literatura os significados e as origens dos ciclos e da progressão continuada, verificou-se que esses conceitos são distintos e não complementares, seja pelas diferentes finalidades, seja pela natureza de origem.

Com o intuito de entender o percurso histórico dos conceitos, será apresentada uma síntese das origens, dos significados e das finalidades tanto da organização do ensino em ciclos quanto da progressão continuada, ${ }^{2}$ pois, conforme Hamilton (1992), no discurso pedagógico há palavras que se tornam "lugares-comuns" e, como tal, precisam ser trazidas para a análise, pois, caso contrário, correm o risco de que suas origens, sua evolução e seu caráter histórico fiquem ocultos. No caso dos ciclos e da progressão continuada, esses conceitos têm se tornado lugares-comuns e, ao mesmo tempo, pontos conceituais de referências (Hamilton, 1992), cujas raízes e finalidades precisam ser investigadas para não se incorrer no risco de torná-los expressões reconhecidas como sinônimos, uma vez que a junção desses conceitos foi realizada pela linguagem oficial da SEE.

\footnotetext{
${ }^{1} \mathrm{Na}$ literatura aparecem os termos "ciclos de aprendizagem", "ciclos de formação humana", "escola ciclada" e "ciclos de desenvolvimento". Uma descrição mais aprofundada da presente discussão pode ser encontrada em Mainardes (2007).

${ }^{2}$ Vale ser ressaltado que, embora as considerações em torno da promoção automática não sejam o foco do presente texto, algumas ponderações sobre tal temática serão brevemente desenvolvidas mais adiante.
} 
É justamente a discussão sobre a sedimentação das prescrições via linguagem oficial que justifica a opção pelo referencial teórico utilizado, a saber: a teoria crítica da sociedade, mais precisamente as noções de "fechamento dos universos político e da locução" e "pensamento unidimensional", apresentadas por Herbert Marcuse no livro A ideologia da sociedade industrial (1967), segundo o qual, devidos aos fechamentos impostos pelo sistema, há a necessidade de compreensão dos reais significados dos conceitos, que acabam "perdendo" sua história, suas relações e seus significados, porque "(...) o conceito nega a identificação da coisa com a sua função; distingue aquilo que a coisa é das funções contingentes dessa coisa na realidade estabelecida" (Marcuse, 1967, p. 101).

Surge assim um padrão de pensamento e comportamentos unidimensionais no qual as ideias, as aspirações e os objetivos que por seu conteúdo transcendem o universo estabelecido da palavra e da ação são repelidos ou reduzidos a termos desse universo. (Marcuse, 1967, p. 32).

Diante da "unidimensionalidade" de comportamentos por meio da linguagem, torna-se pertinente refletir sobre os conceitos que adentram o campo educacional, ou seja, como se consubstancia a reflexão marcuseana sobre os conceitos norteadores da educação, uma vez que as ponderações desse autor assinalam a perda de discussão dos conceitos e seus significados, quando sancionados pelos intelectuais:

O significado é fixado, falsificado e cumulado. Uma vez transformado em vocábulo oficial, constantemente repetido no uso geral, "sancionado" pelos intelectuais, terá perdido todo valor cognitivo e serve meramente ao reconhecimento de um fato indiscutível. (Marcuse, 1967, p. 100-101).

Mediante essa "sanção" dos intelectuais - que no caso da presente discussão são os elaboradores da reorganização do ensino na rede estadual paulista -, pode-se postular que o potencial de reflexão se esvai, limitando-se à referência de um fato, que passa então a não ser questionado.

O pensamento marcuseano auxilia na discussão sobre a forma como os órgãos oficiais realizam a junção e padronização de conceitos. Alerta o autor que estes se apoderam da linguagem política, que se torna

[...] um hábito de pensar fora da linguagem científica e tecnológica, tal raciocínio molda a expressão de um behaviorismo social e político. Nesse universo behaviorista, as palavras e os conceitos tendem a coincidir, ou antes, o conceito tende a ser absorvido pela palavra. Aquele não tem qualquer outro conteúdo que não o designado pela palavra no uso anunciado e padronizado, esperando-se que a palavra não tenha qualquer outra reação que não o comportamento anunciado e padronizado. A palavra se torna um clichê e, como tal, governa a palavra ou a escrita; assim, a comunicação evita o desenvolvimento genuíno do significado. (Marcuse, 1967, p. 94-95).

Por meio da perda de significado do conceito, coisas distintas são juntadas com o intuito de "padronizar" os pensamentos dos sujeitos, valendo-se da palavra. Isso remete ao que o autor denominou de pensamento unidimensional, que 
[...] é sistematicamente promovido pelos elaboradores da política e seus provisionadores de informação em massa. O universo da palavra, destes e daqueles, é povoado de hipóteses autoavaliadoras que, incessantemente e monopolisticamente repetidas, se tornam definições ou prescrições hipnóticas. (Marcuse, 1967, p. 34).

Tendo como referência os fechamentos realizados pelos elaboradores das políticas educacionais, aponta-se a necessidade de refletir sobre os reais significados históricos dos conceitos, uma vez que, conforme Marcuse (1967), conceitos com surgimento e funções distintas acabam sendo introjetados como sinônimos no modo de pensar dos sujeitos.

Dessa forma, serão expostos a seguir: o surgimento e significado dos ciclos; uma breve explanação sobre o discurso em torno da promoção automática na educação paulista; a implantação da progressão continuada; o momento da junção do conceito de ciclos com o de progressão continuada; e a forma utilizada pelos gestores da política educacional da rede pública estadual paulista para realizar tal junção.

\section{O percurso dos ciclos}

Ao buscar na literatura o surgimento da organização do ensino por ciclos, alguns autores como Azanha (1987) e Almeida e Mahoney (2003) afirmam que essa proposta tem sua origem com Henry Wallon, na França, como apresentado no plano Langevin-Wallon, de 1947. Destaca Machado (1989, p. 186) que "o projeto de certa forma refletia uma proposta de compromisso entre partidos políticos e forças ideológicas que estiveram presentes na luta pela libertação da França".

Após três anos de pesquisa, em 1947 foi apresentado o plano LangevinWallon, que tinha como objetivo a reconstrução democrática da França após a Segunda Grande Guerra Mundial por meio de uma ruptura com a escolaridade clássica de transmissão enciclopédica de conhecimentos. Ele propunha uma abertura à formação do homem integrado à humanidade, mediante uma educação nacional que teria como objetivo servir tanto aos interesses da comunidade como cada um dos seus membros (Merani, 1977b).

Ao prever a organização do ensino em três ciclos, o plano LangevinWallon é tido como precursor desse modelo. A gênese da organização por ciclos estava atrelada à meta principal de uma "escola única" à qual todas as crianças teriam acesso (Merani, 1977b).

O plano Langevin-Wallon propõe que, desde as imensas aglomerações até as menores povoações, a escola deve ser um centro de difusão de cultura. Para tanto, os autores dividem a escola em três ciclos. O primeiro ciclo - dos 3 aos 11 anos, sendo a obrigatoriedade escolar fixada aos 6 anos - tem como objetivo fazer a criança compreender o estudo físico e humano, permitindo-lhe situar-se no espaço e no tempo. O segundo ciclo - dos 11 aos 15 anos - é um período de orientação, que tem como objetivo possibilitar uma observação metódica das crianças para descobrir suas aptidões e permitir sua orientação. O terceiro ciclo - dos 15 aos 18 anos - é 
o período de determinação, quando será consagrada a formação do cidadão e do trabalhador (Merani, 1977b).

A justificativa da organização por ciclos do plano Langevin-Wallon de 1947 traz um fator relevante sobre a intencionalidade da proposta, uma vez que, no plano, a égide da organização da escola em ciclos estava pautada na busca de uma escola única e democrática para todos. Tal escola democrática estava associada aos princípios norteadores da proposta, que contemplava a democratização do ensino, na qual a diversidade das funções não seria regulada pela classe social, mas, por exemplo, pela capacidade de desempenhar funções que "serve o interesse coletivo ao mesmo tempo em que o bem-estar individual" (Merani, 1977b, p. 178).

Vale destacar alguns fatores relevantes presentes no plano LangevinWallon de 1947, tais como:

a) o número efetivo de alunos por sala, que em nenhum caso poderia ser superior a vinte e cinco, pois o professor deveria utilmente ocupar-se de cada aluno, o que não seria possível com um número maior;

b) a gratuidade do estudo, não apenas limitada às despesas com estudos, mas na oferta de um pré-salário para o adolescente que cursaria o terceiro ciclo do primeiro grau, uma vez que nessa fase o adolescente pertencente às famílias operárias iniciava-se no trabalho para ajudar no orçamento familiar, de modo que, sem essa ajuda, muitos poderiam não continuar os estudos em virtude da necessidade do dinheiro;

c) a dignidade e o aumento do número de professores em todos os graus;

d) a construção de novos prédios escolares.

No âmbito econômico, os elaboradores do plano expuseram com veemência as preocupações com o financiamento das medidas sociais, pois somente com a concretização delas seria possível a real efetivação do plano, que o futuro da economia e da cultura trataria de preparar e defender.

Conforme exposto, as preocupações do plano Langevin-Wallon de 1947 transitavam desde o número de alunos por sala até questões econômicas para a sustentação do plano. Previa-se também uma educação que contemplasse a todos, independentemente de etnia, religião ou posição social, conforme aptidões de cada um, oferecendo ao aluno condições para desenvolver-se intelectual e moralmente. O plano apontava que o ensino deveria "oferecer a todos possibilidades iguais de desenvolvimento, abrir para todos o acesso à cultura, democratizar-se" (Merani, 1977b, p. 178).

A educação organizada por ciclos foi justificada no plano com base em alguns princípios gerais:

1) justiça: todas as crianças, independentemente de suas origens familiares, sociais, étnicas, têm igual direito ao desenvolvimento de sua personalidade; 
2) todas as formas de trabalhos sociais têm igual valor, dessa forma, o trabalho manual e a inteligência prática não devem ser menosprezados em relação a outras capacidades;

3) a orientação da ação educativa deve estar de acordo com os fins de formação e harmonização humanas do indivíduo em questão;

4) não há especialização profissional sem cultura geral.

Conforme Wallon (1975), "a especialização não pode ser obstáculo para a compreensão de problemas mais amplos (...), uma sólida cultura libera o homem dos limites (estreitos) da técnica", pois quanto mais especializada, mais cedo se torna obsoleta. Só com base na cultura geral o indivíduo poderá superar esse movimento.

Entre os diversos temas relevantes aqui apresentados sobre o plano Langevin-Wallon, um fator de cunho ideológico e político vale ser enfatizado: ao organizar a escola por ciclos, tinha claramente explicitado como intuito central a busca por uma melhor formação dos alunos por meio de uma escola única, com vistas à democratização do ensino. Dessa forma, a proposta de seus autores justificava-se pelo fato de que a educação deve ser adaptada ao homem e não aos interesses de cunho econômico, como ocorre na educação brasileira atualmente.

Embora a afirmação referente aos interesses que a educação brasileira vem atendendo pareça ser muito direta, para sustentá-la serão analisados a seguir os significados e as "finalidades" a que "vieram responder" os primeiros postulados sobre o rompimento com o modelo seriado na rede pública estadual paulista, em suma, as discussões e justificativas que sedimentaram a implantação da progressão continuada a partir de 1998. No entanto, antes de adentrar especificamente nos postulados referentes à progressão continuada, discorre-se brevemente sobre a promoção automática que, do ponto de vista histórico, está no cerne dos debates que desencadearam a progressão continuada.

\section{A promoção automática no Estado de São Paulo: um breve retrospecto}

Viégas e Souza (2012) apontam que os discursos em torno da promoção automática tiveram início no Brasil por meio da carta aberta de Sampaio Dória para Oscar Thompson, publicada em 1918.

Diante de um cenário educacional problemático entre as décadas de 1920 e 1950, no Brasil, a promoção automática foi apresentada como uma alternativa viável para conter as altas taxas de repetência, regularizar o fluxo e evitar o desperdício de recursos. Contudo, essas ideias não ganharam força e acabaram não prevalecendo. Tal discussão só foi retomada a partir da década de 1950, mediada pelos estudos e artigos publicados por Almeida Junior (1957) e Dante Moreira Leite (1959).

Viégas e Souza (2012) apontam que uma experiência pioneira na abolição da reprovação na rede estadual paulista foi elaborada no final da 
década de 1950 e implantada no início de 1960, no Grupo Experimental da Lapa, escola que funcionava como unidade oficial de pesquisas da Secretaria da Educação.

Outra experiência realizada pela SEE foi a chamada reforma do ensino primário (Ato $\mathrm{n}^{\circ}$ 306, de 19 de novembro de 1968), que compreendia como sua principal alteração a modificação do sistema seriado do ensino, eliminando a reprovação do aluno entre a $1^{\mathrm{a}}$ e a $2^{\mathrm{a}}$ séries (nível I) e entre a $3^{\mathrm{a}}$ e a $4^{\mathrm{a}}$ séries (nível II). A promoção de um nível para outro seria feita mediante o alcance dos mínimos fixados nos programas de ensino. Segundo Arelaro (1988), apesar de o Ato 306/68 nunca ter sido expressamente revogado, em 1972 a organização em níveis deixou de existir. Conforme a autora, isso ocorreu porque o grupo favorável à medida "cai" no início de maio de 1970, sob a suspeita de subversão. Dessa forma, conforme atesta Mainardes (1998), a discussão sobre a proposta de promoção automática vai ressurgir no Estado de São Paulo somente na década de 1980.

No início da década de 1980, em meio a um conturbado momento político, iniciaram-se no Estado de São Paulo as discussões sobre uma reformulação do ensino nas séries iniciais do ensino fundamental. Tal movimento desencadeou no ano de 1984 a criação e implantação do ciclo básico. Na proposta inicial do ciclo básico, buscou-se romper com o modelo de seriação presente nas duas séries iniciais do primeiro grau. A razão dessa junção foi o fato de que o índice de reprovação na primeira série chegava, em algumas escolas, a cerca de 60\% (Azanha, 1987).

Após esse breve retrospecto das assertivas em torno do rompimento do modelo seriado na rede pública estadual paulista, destaca-se a reformulação ocorrida no ano de 1998

\section{A progressão continuada na rede pública de ensino estadual paulista}

Dias-da-Silva e Lourencetti (2002, p. 23) enfatizam que a implantação da organização do ensino em ciclos com progressão continuada foi "certamente o período de maior efervescência nas escolas públicas paulistas nos últimos anos", ou seja, a reforma que mais impactou a vida escolar.

Fator de fortes discussões políticas e acadêmicas, ${ }^{3}$ a progressão continuada evidencia algumas razões veiculadas oficialmente, mais precisamente, entre outras, a redução dos índices de repetência e evasão. Isso ficou patente quando, no ano de 1997, o Conselho Estadual de Educação aprovou a Indicação $n^{\circ}$ 8/97 e a Deliberação $n^{\circ}$ 9/97, que implantaram o

${ }^{3}$ Embora esse não seja o foco desta pesquisa, um fator a ser ressaltado é que, na disputa eleitoral para o governo do Estado de São Paulo de 2010, os dois principais concorrentes se manifestaram sobre a questão da progressão continuada, dos quais um a defendia enquanto o outro tinha como uma de suas metas extingui-la. regime de progressão continuada na rede pública estadual paulista a partir do ano de 1998, pelo qual as reprovações dos alunos deveriam ocorrer primordialmente nos anos finais dos ciclos $-4^{\mathrm{a}}$ e $8^{\mathrm{a}}$ séries.

Alguns estudiosos da progressão continuada têm feito diversas críticas em relação ao que ela veio atender no Estado de São Paulo. Estudioso dessa temática, Freitas (2003, p. 9), ao posicionar-se sobre a progressão continuada e suas finalidades, afirma que ela "tem como perspectiva 
central a correção de fluxo". Dias (2004, p. 63), ao posicionar-se sobre sua proveniência, destaca que

a progressão continuada, camuflada de organização escolar em ciclos, implica a priorização não do aprendizado, mas, com a promoção automática, a diminuição das taxas de repetência e evasão, não o aumento dos investimentos, mas a racionalização destes.

Os estudos de Freshe (2001), Dias (2004) e Vasconcelos (2007), embora com diferentes referenciais teóricos e de análise, identificaram duas vertentes/consequências da progressão continuada. A primeira diz respeito à diminuição dos gastos pela otimização de recursos por meio da regularização do fluxo de alunos da rede (idade/série), pois a evasão e a repetência eram consideradas pela SEE/SP "perniciosos ralos por onde se desperdiçam os preciosos e poucos recursos financeiros da educação" (Bitar, 1998, p. 13). A segunda está vinculada ao surgimento de um novo tipo de exclusão dos alunos no interior da escola, uma vez que, em razão de estes não terem aprendizagem adequada - contrariamente ao discurso oficial -, esse modelo vem contribuindo para a exclusão social dos estudantes em detrimento da efetiva progressão da aprendizagem, pois, quando se faz com que os alunos prossigam os estudos sem dar-lhes as mínimas condições de aprenderem os conteúdos escolares, pode-se entender que se está negligenciando a responsabilidade de oferecer educação "de qualidade", tão aclamada pelos órgãos gestores. Mediante as constatações dos estudos acima mencionados, pode-se postular que a racionalização de recursos econômicos parece ter sido o ponto de partida dos órgãos gestores, que, por trás de discursos democráticos, acabaram de certa forma camuflando os interesses econômicos dessa política educacional.

As assertivas apresentadas pelos pesquisadores acima mencionados podem ser retomadas, pois, além da questão em torno dos interesses de racionalização de recursos financeiros, a questão em prol da ordem e do "crescimento econômico" e em detrimento da formação dos indivíduos, que também estabelece claramente o motivo da implantação da progressão continuada, pode ser expressa na Indicação CEE no 8/97 - Conselho Pleno, aprovada em 30 de julho de 1997:

Uma mudança dessa natureza deve trazer, sem dúvida alguma, benefícios tanto do ponto de vista pedagógico como econômico. Por um lado, o sistema escolar deixará de contribuir para o rebaixamento da autoestima de elevado contingente de alunos reprovados. Reprovações muitas vezes reincidentes na mesma criança ou jovem, com graves consequências para a formação da pessoa, do trabalhador e do cidadão. Por outro lado, a eliminação da retenção escolar e decorrente redução da evasão deve representar uma sensível otimização dos recursos para um maior e melhor atendimento de toda a população [...] O custo correspondente a um ano de escolaridade de um aluno reprovado é simplesmente um dinheiro perdido. Desperdício financeiro que, sem dúvida, afeta os investimentos em educação, seja na base física (prédios, salas de aula e equipamentos), seja, principalmente, nos salários dos trabalhadores do ensino. Sem falar do custo material e psicológico por parte do próprio aluno e de sua família. 
Ainda da perspectiva de política educacional e social, é sabido que o Brasil precisa, com a maior rapidez possível, elevar os níveis médios de escolaridade dos seus trabalhadores. A educação básica e a qualificação profissional constituem requisitos fundamentais para o crescimento econômico, para a competitividade internacional e, como meta principal, para a melhoria da qualidade de vida da população. (São Paulo. SEE. Indicação nº 8, 1997, p. 6, grifos do autor).

Os excertos acima deixam claro que a progressão continuada é oriunda de uma política educacional norteada pelas finalidades econômicas, tanto pela racionalização de recursos quanto pela "elevação" da escolaridade dos trabalhadores para atender às demandas do mercado.

Fator que merece destaque é que a racionalização de recursos econômicos e a qualificação dos trabalhadores das classes menos abastadas parecem ter sido o ponto de partida dos órgãos gestores.

Dessa forma, constata-se que tanto os autores aqui mencionados quanto o disposto no discurso oficial - Indicação $n^{\circ} 8$ (São Paulo. CEE, 1997) - confluem para a assertiva de que a progressão continuada tem como ponto referencial a racionalização de gastos. Destaca-se, porém, que o discurso oficial não se poupou de assumir que a racionalização de recursos foi sua finalidade de ordem maior, o que permite sinalizar que o discurso "psicologizante" em torno dos danos causados pela reprovação pode apenas ter sido uma forma de justificar essa racionalização.

\section{A junção dos ciclos com a progressão continuada no Estado de São Paulo}

Dadas as diferentes origens, funções e finalidades da organização do ensino em ciclos proposta no plano Langevin-Wallon e os primeiros postulados da progressão continuada no Estado de São Paulo, o que vale ser enfatizado e discutido é o fato de que o Conselho Estadual de Educação, no ano de 1997, aprovou a Indicação no 8/97 e a Deliberação no 9/97, que implantaram o regime de progressão continuada e, consequentemente, os ciclos no sistema de educação.

A justificativa da SEE para a organização da educação em ciclos configurou-se como uma política educacional a fim de superar a tradicional organização escolar seriada, considerada seletiva e excludente, responsável pelos altos índices históricos de repetência e evasão escolar.

Ao organizar o ensino fundamental em dois ciclos em 1998, a SEE implantou a progressão continuada, que, por sua vez, teve como base organizacional os ciclos e não o ano civil. Isso significa que os elaboradores da política educacional paulista conceberam os ciclos e a progressão continuada como facetas de uma mesma forma de organização.

Dias (2004), ao discorrer sobre o porquê de os formuladores da política estadual paulista terem estabelecido relação entre a organização do ensino por ciclos e a progressão continuada, afirma que os ciclos tornaram-se por si mesmos progressistas, e simplesmente criticá-los passou a ser 
considerado um descompasso pedagógico. Os ciclos foram tomados como verdade pedagógica, constituindo-se como forte atributo legitimador da progressão continuada. Dessa forma, esquece-se da nítida diferença entre ciclos e progressão continuada.

Autor que tem discutido a temática da diferença tanto no surgimento quanto nas diferentes funções dos ciclos e da progressão continuada, Freitas (2004b) afirma que a progressão continuada já estava na agenda liberal desde que esta se apropriou do lema "Educação para Todos" no início da década de 1990, ao passo que os ciclos foram inseridos em nossa realidade mais frequentemente a partir de uma perspectiva crítico-social. Enfatiza Freitas (2004b, p. 6) que o surgimento da progressão continuada "(...) teve como objetivo meramente lidar com os problemas educacionais dentro de uma perspectiva economicista: liberando fluxos e enxugando custos". Quanto aos ciclos:

Diferentemente da progressão continuada, os ciclos propõem alterar os tempos e os espaços da escola de maneira mais global, procurando ter uma visão crítica das finalidades educacionais da escola. Está em jogo mais do que simplesmente liberar fluxos, ou sair-se bem em avaliações de sistema ou, ainda, tirar a avaliação formal juntando séries em planejamentos plurianuais. (Freitas, 2004b, p. 11).

Freitas (2002a, p. 301) também reforça que o regime de progressão continuada tem a finalidade de reduzir custos econômicos, sociais e políticos das formas de exclusão objetivas - repetência e evasão - sem alterar a seletividade da escola, criando um "campo de exclusão subjetiva". Já os ciclos devem ser mecanismos de resistência à lógica seriada, mas precisam ser vistos como oportunidades para se elevar a conscientização dos professores, alunos e pais, revelando a estes as reais travas para o desenvolvimento da escola e da sociedade, "e não apenas serem vistos como uma solução técnico-pedagógica para a repetência" (Freitas, 2002a, p. 321). No entanto, ao manifestar-se sobre a associação entre os ciclos e a progressão continuada no Estado de São Paulo, em comparação com outros estados que também realizaram a organização do ensino em ciclos, Freitas (2004b) denuncia que em São Paulo o caso é mais grave, já que, com a implantação da progressão continuada, corre-se o risco de comprometer a ideia de ciclo e, por conseguinte, de os dois conceitos serem sedimentados no pensamento de pais, alunos e professores como se tivessem a mesma origem e função (Freitas, 2004b).

Nessa discussão acerca da sedimentação das prescrições oficiais e seus usos, recorre-se a Marcuse, que, ao discorrer sobre a junção de conceitos e seus usos, aponta para a necessidade da análise dos significados das palavras - nesse caso, ciclos e progressão continuada - a fim de explicitar seu sentido histórico e político, afirmando que "se o comportamento linguístico bloqueia o desenvolvimento conceptual, se ele milita contra a abstração e a mediação, se se rende aos atos imediatos, repele o reconhecimento dos fatos, bem como do conteúdo histórico destes" (Marcuse, 1967, p. 102). 
Essa perda de significado ganha relevância na presente discussão, pois, após a promulgação da LDB, afirma Mainardes (2006), a inserção dos ciclos representou, de um lado, mudanças no currículo e orientações metodológicas para o processo de ensino-aprendizagem. Por outro lado, a política foi incorporada de forma conservadora, gerando o regime de progressão continuada. Ainda de acordo com o autor, a emergência dessa versão conservadora está relacionada com a Lei no 9.394/96, a qual permite que os sistemas educacionais organizem a escolaridade em séries, ciclos ou no regime de progressão continuada, entre outras formas de organização contempladas na referida lei, mais especificamente no artigo 23, uma vez que a LDB deixa algumas brechas no tocante às formas de organização escolar, enquanto no artigo 32 legisla o seguinte:

$\S 1^{\circ}$. É facultado aos sistemas de ensino desdobrar o ensino fundamental em ciclos.

$\S 2^{\circ}$. Os estabelecimentos que utilizam progressão regular por série podem adotar no ensino fundamental o regime de progressão continuada, sem prejuízo da avaliação do processo de ensino-aprendizagem, observadas as normas do respectivo sistema de ensino. (Brasil. Lei n. 9.394, 1996, art. 32).

Nesse sentido, pode-se afirmar que todas as concepções de organização - ciclos ou séries - devem necessariamente ser orientadas pelo regime de progressão continuada, ou seja, mesmo na organização do ensino em ciclos, estes devem estar associados à progressão continuada. O que se denota é o uso da linguagem oficial - via legislação - para incutir a progressão continuada associada aos ciclos.

Ao discorrer sobre o uso da linguagem em afirmações que visam sedimentar os pensamentos dos indivíduos, Adorno (2006, p. 65-66) afirma:

Nexos pseudológicos e pseudocausais são produzidos por meio de palavras que unem as frases entre si na superfície da linguagem, mas no plano da reflexão sobre o objeto revelam-se totalmente desprovidas de conteúdo; assim, por exemplo, a partir de duas sentenças, uma é apresentada como consequência da outra.

Mediante as ponderações do autor, pode-se inferir que a associação entre ciclos e progressão continuada presente na legislação coloca-os um como consequência do outro. Isso ganha caráter de complementariedade nas assertivas dos autores da proposta, pois, no artigo Quem tem medo da progressão continuada? Ou melhor, a quem interessa o sistema de reprovação e exclusão social?, Rose Neubauer - secretária da Educação na época da implantação da progressão continuada -, ao fazer menção a intelectuais que propuseram a introdução da política de ciclos com progressão continuada na educação brasileira, enfatiza que

essas eminentes figuras que propuseram a aprendizagem em progressão continuada por ciclos não são passíveis de serem identificadas como demagogos ou malandros como pode a alguns parecer. (Neubauer, 2001). 
Por trás da defesa dos intelectuais que compactuam de suas ideias, a então secretária da Educação situa os ideários de ciclos e progressão continuada como complementares, ou seja, para justificar a formulação política, realiza a junção de conceitos com surgimentos e finalidades distintas.

Na política adotada pela SEE há outro equívoco no que diz respeito a essa generalização. Na Deliberação do Conselho Estadual de Educação $\mathrm{n}^{\circ} 9$ de 1997, os legisladores reconhecem e destacam que entre as inovações produzidas pela LDB se incluem os ciclos e a progressão continuada, sobre as quais, embora sejam medidas distintas, o referido documento afirma o seguinte:

A experiência dos ciclos, tanto na rede estadual (ciclo básico de 1984) quanto na rede municipal de São Paulo (1989-1992), tem demonstrado que a progressão continuada contribui positivamente para melhorar o processo de ensino e para obtenção de melhores resultados de aprendizagem. (São Paulo. CEE. Deliberação no 9, 1997 - grifos do autor).

Nos exemplos acima apontados - no artigo 32 da LDB, no artigo da secretária da Educação (Neubauer, 2001) e na Deliberação no 9/97 do Conselho Estadual de Educação -, fica evidente a junção dos ciclos com a progressão continuada pelos autores dos textos, neste caso representantes da SEE. O pensamento de Marcuse auxilia na compreensão da forma como os conceitos são introjetados no modo de pensar dos sujeitos. Para o autor, a linguagem dos gestores "milita contra o desenvolvimento" e a "expressão dos conceitos", e, diante disso, "em sua imediação e objetividade, impede o pensamento conceptual; impede, assim, de pensar. Pois o conceito não identifica a coisa e sua função" (Marcuse, 1967, p. 101). Isso se dá devido ao fechamento do universo da locução:

Elementos mágicos, autoritários e rituais invadem a palavra e a linguagem. A locução é privada das mediações que são as etapas do processo de cognição e avaliação cognitiva. Os conceitos que compreendem os fatos, e desse modo, transcendem estes, estão perdendo sua representação linguística autêntica. Sem tais mediações, a linguagem tende a expressar e a promover a identificação imediata da razão e do fato, da verdade e da verdade estabelecida, da essência e da existência, da coisa e da sua função. (Marcuse, 1967, p. 93).

As reflexões aqui expostas corroboram para o entendimento de que os conceitos "ciclos" e "progressão continuada", nos discursos oficiais, assumem certa semelhança e mesclam-se entre si. No entanto, tanto na busca, já realizada neste texto, pelo surgimento histórico dos conceitos quanto na posição dos autores que na atualidade aprofundaram seus estudos sobre a temática, verificou-se que há diferenças tanto no surgimento quanto nas finalidades dos ciclos e da progressão continuada, de modo que entre os termos há aspectos contraditórios. 


\section{Considerações finais}

À guisa de algumas considerações e, longe da pretensão de esgotar o assunto, destacam-se as diferenças substanciais, de um lado, nas finalidades declaradas da progressão continuada e, de outro, nos postulados presentes na organização do ensino em ciclos proposta no plano Langevin-Wallon. É possível constatar isso, uma vez que o motor da discussão na França - por meio do plano Langevin-Wallon - era a necessidade de uma escola democrática visando o acesso à educação para crianças de diferentes classes sociais, a permanência e a continuidade dos alunos na escola, a expansão do ensino elementar e a junção do primário com o secundário; no Brasil, as discussões tiveram como justificativa os elevados índices de reprovação, evasão escolar e racionalização de recursos e menos a questão da democracia.

Freitas (2004) faz críticas à junção desses conceitos e, por conseguinte, caracteriza a progressão continuada como um sistema excludente e hierarquizado, uma vez que promove a autoexclusão pela inclusão física, enquanto no ensino organizado por ciclos a educação torna-se um direito de todos e obrigação do Estado.

As discussões aqui apresentadas sobre as tênues e distorcidas justificativas dos propositores para associar conceitos com finalidades e surgimentos distintos - ciclos e progressão continuada - ganham caráter de afirmação em Horkheimer e Adorno (1985), que enfatizam haver uma estrita relação entre as formas de pensamento dos sujeitos diante dos fatos e a forma de pensar dos dominantes - nesse caso, os elaboradores da "reforma" da organização escolar no Estado de São Paulo -, de modo que as formas de pensar são sedimentadas no uso que estes fazem da linguagem. Os autores destacam:

É característico de uma situação sem saída que até mesmo o mais honesto dos reformadores, ao usar uma linguagem desgastada para recomendar a inovação, adopta também o aparelho categorial inculcado e a má filosofia que se esconde por trás dele, e assim reforça o poder da ordem existente que ele gostaria de romper. (Horkheimer; Adorno, 1985, p. 14).

Diante das discussões aqui assinaladas e da citação anterior, cabe uma reflexão dual: de um lado, não se pode afirmar que os propositores da junção e implantação dos ciclos com a progressão continuada tiveram como objetivo somente a racionalização de recursos; de outro, ao realizarem a junção dos ciclos com a progressão continuada - ostentando a mudança na forma de avaliação por meio de uma justificativa de cunho psicológico, que, mais precisamente, se fundamentava nos danos psicológicos causados pelo antigo modelo de avaliação que gerava a reprovação -, a reforma da organização do ensino fixou-se mais na busca de suas próprias justificativas, em detrimento de questões voltadas especificamente para a melhoria da qualidade da educação. A discussão sobre o oferecimento de uma melhor formação para os alunos foi secundarizada diante das tentativas de justificar, 
ora pela psicologia, ora pelo racionamento de recursos, a mudança de organização do ensino em séries para ciclos com progressão continuada.

Em meio a essa miscelânea de argumentos, a SEE/SP utilizou-se da linguagem para realizar a junção de conceitos com surgimentos e finalidades distintas, o que permite apontar a necessidade de se investigar como esses conceitos distintos são concebidos pelos indivíduos que são os interlocutores das prescrições oficiais no cotidiano escolar - os professores.

\section{Referências bibliográficas}

ADORNO, T. W. Educação e emancipação. Trad. Wolfgang Leo Maar. Rio de Janeiro: Paz e Terra, 2006.

ALMEIDA JÚNIOR, A. F. Repetência ou promoção automática? Revista Brasileira de Estudos Pedagógicos, Brasília, DF, v. 27, n. 65, p. 3-15, jan./ mar. 1957.

ALMEIDA, L. R.; MAHONEY, Abigail A. (Org.). Henri Walllon: psicologia e educação. São Paulo: Loyola, 2003.

ARELARO, L. R. G. A (ex) tensão do ensino básico no Brasil: o avesso de um direito democrático. 1988. 299 f. Tese (Doutorado em Educação) Faculdade de Educação, Universidade de São Paulo, São Paulo, 1988.

AZANHA, J. M. P. Educação: alguns escritos. São Paulo: Ed. Nacional, 1987.

BITAR, Hélia A. de Freitas; FARES, Jacyra; CONBOLATO, Maria Conceição; CUNHA, Maria Cristina A. Alves da; FERREIRA, Maria José do Amaral. Sistema de avaliação de rendimento escolar do Estado de São Paulo: implantação e continuidade. Série Idéias, São Paulo, n. 30, p. 9-20, 1998.

BRASIL. Lei no 9.394, de 20 de dezembro de 1996. Estabelece as diretrizes e bases da educação nacional. Diário Oficial da União, Brasília, DF, 23 dez. 1996. Disponível em: <http://www.planalto.gov.br/ccivil_03/ leis/19394.htm>.

DIAS, V. E. M. A organização escolar em ciclos: um estudo sobre a progressão continuada do Estado de São Paulo. 2004. 148 f. Dissertação (Mestrado em Educação) - Universidade Federal de São Carlos, São Paulo, 2004. 
DIAS-DA-SILVA, M. H. F.; LOURENCETTI, G. C. A voz dos professores e algumas reformas educacionais nas séries finais do ensino fundamental: desencontros ou impasses? In: SAMPAIO, Maria das Mercês Ferreira (Org.). O cotidiano escolar frente às políticas educacionais. Araraquara: JM, 2002. p. 19-43.

FREITAS, L. C. A internalização da exclusão. Educação \& Sociedade, Campinas, v. 80, p. 301-327, out. 2002a.

FREITAS, L. C. Ciclos de progressão continuada: vermelho para as políticas públicas. Revista Eccos, São Paulo, v. 4, n. 1, p. 79-93, jun. 2002b.

FREITAS, L. C. Ciclos, seriação e avaliação: confronto de ideias lógicas. São Paulo: Moderna, 2003.

FREITAS, L. C. A avaliação e as reformas dos anos de 1990: novas formas de exclusão, velhas formas de subordinação. Educação \& Sociedade, Campinas, v. 25, n. 86, p. 133-170, 2004a.

FREITAS, L. C. Ciclos ou séries? O que muda quando se altera a forma de organizar os tempos-espaços da escola? In: REUNIÃO ANUAL DA ANPED, 27., 2004, Caxambu, MG. Anais eletrônicos... Caxambu, MG, 2004b. Disponível em: <http://27reuniao.anped.org.br/diversos/te_luiz_ carlos_freitas.pdf $>$.

FRESHSE, E. Democratização em xeque?: vicissitudes da progressão continuada do ensino paulista em 1999. 2001. Dissertação (Mestrado em Educação) - Universidade de São Paulo, São Paulo, 2001.

HAMILTON, D. Sobre as origens dos termos classe e curriculum. Teoria \& Educação, Porto Alegre, n. 6, p. 33-52, 1992.

HORKHEIMER, M.; ADORNO, T. W. Dialética do esclarecimento. Trad. Guido Antonio de Almeida. Rio de Janeiro: Jorge Zahar, 1985.

LANGEVIN, P.; WALLON, H. Plano de reforma Langevin-Wallon. In: MERANI, Alberto L. Psicologia e pedagogia: as idéias pedagógicas de Henri Wallon. Lisboa: Notícias, 1977. p. 175-221.

LEITE, Dante Moreira. Promoção automática e adequação do currículo ao desenvolvimento do aluno. Estudos em Avaliação Educacional, São Paulo, n. 19, p. 5-24, jan./jul. 1959.

MACHADO, L. S. Politécnica, escola unitária e trabalho. São Paulo: Cortez, 1989. 
MAINARDES, J. A promoção automática em questão: argumentos, mudanças e possibilidades. Revista Brasileira de Estudos Pedagógicos, Brasília, DF, v. 79, n.192, p. 16-29, maio/ago. 1998.

MAINARDES, J. Abordagem do ciclo de políticas: uma contribuição para a análise de políticas educacionais. Educação \& Sociedade, Campinas, v. 27, n. 94, p. 1-21, jan./abr. 2006.

MAINARDES, J. Reinterpretando os ciclos de aprendizagem. São Paulo: Cortez, 2007.

MARCUSE, H. A ideologia da sociedade industrial. Trad. Giasone Rebuá. Rio de Janeiro: Zahar, 1967.

MERANI, A. L. Psicologia e alienação. Rio de Janeiro: Paz e Terra, 1977a.

MERANI, A. L. Psicologia e pedagogia: as idéias pedagógicas de Henri Wallon. Lisboa: Notícias, 1977b.

NEUBAUER, R. Quem tem medo da progressão continuada ou melhor, a quem interessa o sistema de reprovação e exclusão social?. 2001. Disponível em: <http://www.crmariocovas.sp.gov.br/int_a.php?t=001>. Acesso em: maio 2012.

SÃO PAULO (Estado). Conselho Estadual de Educação (CEE). Indicação no 8, de 30 de julho de 1997. Regime de progressão continuada. Diário Oficial do Estado de São Paulo, São Paulo, SP, 5 ago. 1997. Seção 1, p. 12-13.

SÃO PAULO (Estado). Conselho Estadual de Educação (CEE). Deliberação $\mathrm{n}^{\circ}$ 9, de 30 de julho de 1997. Institui no Sistema de Ensino do Estado de São Paulo o regime de progressão continuada no ensino fundamental. Diário Oficial do Estado de São Paulo, São Paulo, SP, 5 ago. 1997. Seção 1, p. 12-13.

SÃO PAULO (Estado). Conselho Estadual de Educação (CEE). Indicação $\mathrm{n}^{\circ} 22$, de 17 de dezembro de 1997. Avaliação e Progressão Continuada. Diário Oficial do Estado de São Paulo, São Paulo, SP, 20 dez. 1997. Seção 1, p. 18.

SÃO PAULO (Estado). Secretaria da Educação (SEE). Ato n ${ }^{\circ}$ 306, de 19 de novembro de 1968. Dispõe sobre medida de rendimento no curso primário. Diário Oficial do Estado de São Paulo, São Paulo, SP, 20 nov. 1968. Disponível em: <http://www3.fe.usp.br/secoes/inst/novo/acervo_ jmpa/PDF_SWF/7.pdf $>$. 
SÃO PAULO (Estado). Secretaria de Educação do Estado (SEE).

Resolução $\mathrm{n}^{\circ} 4$, de 15 de janeiro de 1998. Dispõe sobre normas a serem observadas na composição curricular e na organização escolar. Disponível em: <http://www.crmariocovas.sp.gov.br/pdf/diretrizes_ p1083-1087_c.pdf $>$.

VASCONCELOS, L. S. Progressão continuada: educação escolar na ordem neoliberal. 2007. Tese (Doutorado em Educação) - Faculdade de Educação, Universidade Estadual de Campinas, 2007.

VIÉGAS, L. S.; SOUZA, P. R. M. Promoção automática nos anos 1950: a experiência pioneira do Grupo Experimental da Lapa (São Paulo). Educação e Pesquisa, São Paulo, v. 38, n. 2, p. 499-514, abr./jun. 2012.

WALLON, H. Psicologia e educação na infância. Tradução de Ana Rabaça. Lisboa: Estampa, 1975.

Anoel Fernandes, doutorando em Educação pela Pontifícia Universidade Católica de São Paulo (PUC/SP), é professor e coordenador do curso de Pedagogia da Faculdade de Itapecerica da Serra, São Paulo, Brasil. anoelfernandes@ig.com.br

Recebido em 24 de janeiro de 2014.

Solicitação de correções em 30 de julho de 2014.

Aprovado em 1 de outubro de 2014. 